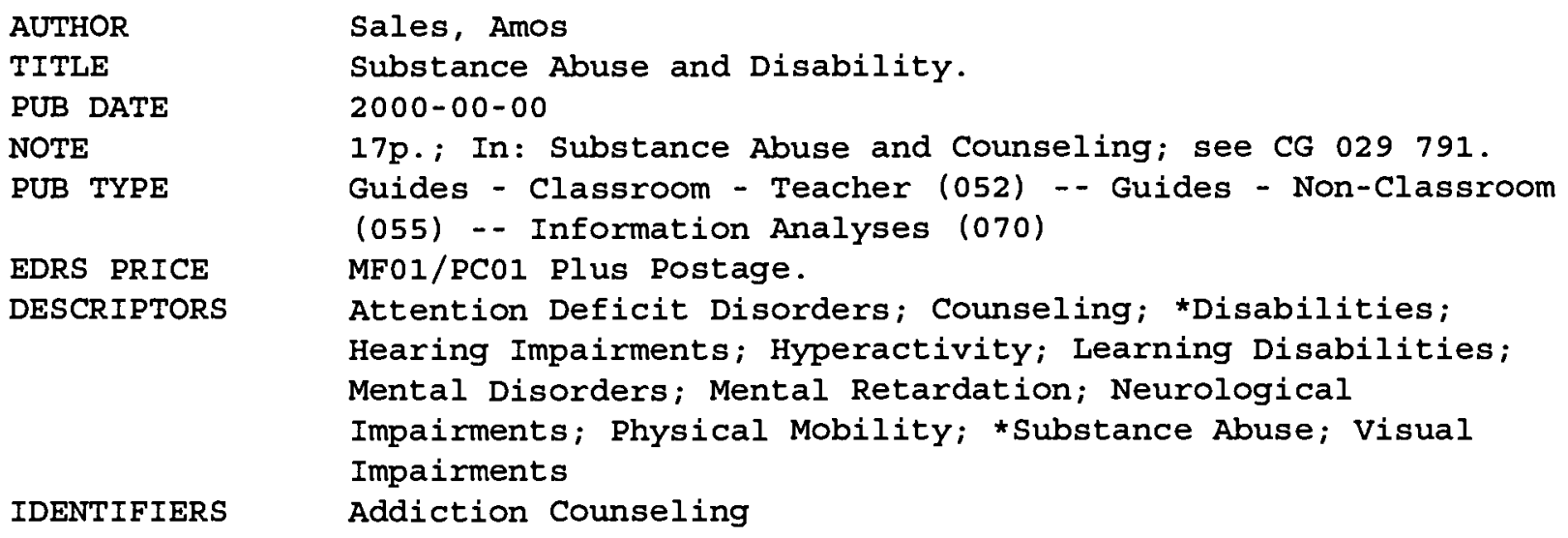




\title{
Substance Abuse and Disability
}

\author{
Amos Sales
}

\begin{tabular}{l} 
U.S. DEPARTMENT OF EDUCATION \\
Ofice of Educational Rosearch and Improvement \\
EDUCATIONAL RESOURCES INFORMATION \\
CENTER (ERIC) \\
$\square$ This document has been reproduced as \\
received from the person or organization \\
originating it. \\
$\square$ Minor changes have been made to \\
improve reproduction quality. \\
\hline Points of view or opinions stated in this \\
document do not necessarily represent \\
official OERI position or policy
\end{tabular}

Substance abuse is widespread and of major impact in our society (SARDI, 1996; Beck, Marr, Taricone, 1994). Estimates are that forty-five million Americans attend one hundred-and-forty different kinds of weekly recovery groups. Another 100 million are trying to help those who are in recovery (Yalom, 1995). Studies, over the past fifteen years, of individuals of various disabilities in the United States (U.S.) show their alcohol and drug abuse is up to three (3) times that of the general population (Connecticut Clearing House, 1998).

Given the above estimates, the expectation of practitioners would be that substance abuse on client's with disability caseloads would be much higher than or at least parallel to what is found in the general population, approximately 1 in 3 clients having a substance abuse problem. However, actual agency service delivery experience with clients known as substance abusers indicates agencies are serving a smaller percentage in their caseloads than in the population. For example, in 1990, over 23,000 (11\%) of clients who were successfully closed from the State-Federal Vocational Rehabilitation (VR) program in the U.S. had primary diagnoses of substance abuse or dependence, with an additional $8,000(4 \%)$ having a secondary substance abuse disability (DeNitto and Schwab, 1991). However, in addition to these diagnoses, Ohlmer (1992) and others have found that a very high (35 to 52) percent of VR caseloads have undiagnosed substance abuse problems. One of these studies (DiNitto \& Schwab, 1991) found, in using the Addictions Severity Index (ASI) to evaluate 86 Texas rehabilitation clients with no substance abuse diagnosis, that $33(38 \%)$ met the ASI ceiteria for alcohol or drug problems. Similar results were found with the SASSI, where $35(25 \%)$ of 138 clients with no substance abuse diagnosis were classified as chemically dependent or chemical abusers. The high percentages of undiagnosed substance abuse problems reflect individuals who are not being provided services appropriate to their problems.

Undiagnosed substance abuse exists on VR caseloads because of two reasons. The substance abuse is either hidden by the client or overlooked by counseling staff. Clients often "hide" their substance abuse problem because of a fear that knowledge of it will result in their not receiving services. Counselors overlook the problem by conscious choice and by inability to perceive it. Once suspected, the counselor often consciously decides not to pursue the problem because her/she believes the client is stigmatized enough without adding a diagnosis of substance abuse. Other conscious choices involve the counselor having a misguided view of acceptance or under time pressure and choosing not to pursue the suspicion of substance abuse as a service delivery problem. Counselors often simply overlook the problem by not perceiving the signs of it. Whether hidden by client choice or overlooked by the counselor, the impact of an undiagnosed substance abuse problem puts the client at a disadvantage, appropriate services are not provided, and failure of service delivery becomes a strong potential.

\section{Prevalence of Substance Abuse}

Estimates of the number of Americans with disabilities range from 35 million (Pope \& Tarlov, 1991) to 49 million (Americans with Disabilities Act, 1990), (Rehabilitation Research \& Training Center on Drugs \& Disability, 1996). These estimates vary depending on how disability is operationally defined. The words disability and handicapped have been used synonymously, but rehabilitation practitioners and communities distinguish between the two. A disability is a physical or mental condition that can be defined by a medical practitioner. Disabilities include blindness or vision impairment, cleft palate, congenital disabilities, deafness or hearing impairments, spinal cord injuries, paraplegia, or quadriplegia, mental disabilities, head injuries or head trauma, learning disabilities, and mental retardation or cognitive impairment. A handicap is a situational or social barrier or obstacle to the person with a disability in achieving his or her maximum level of functioning. Prendergast, Austin, \& Miranda, (1990, p. 2) provide the following distinction between disability and handicap, "a person using a wheelchair is handicapped in traveling throughout the city not because of the wheelchair, but because of the inaccessibility of buses or buildings. The disability cannot be changed, but the handicapping condition can be".

People with disabilities have been identified as one of the nation's largest populations at high risk of alcohol and other drug abuse problems (Prendergast, Austin, \& Miranda, 1990). Studies have suggested that substance abuse is problematic and estimated to be as high as $80 \%$ among some subgroups within population (Boros, 1989; Heinemann, Donohue, Keen, \& Schnoll, 1988; Edgerton, 1986). Between 6 and 13 million Americans are physically or mentally disabled and chemically dependent as well (VSA, 1992, Schwab, 1992). However, there is still limited research on prevalence and effective intervention and prevention strategies. 
While Greer, Roberts, May, and Jenkins (1985) have discussed the problems related to identifying a comprehensive estimate of the incidence of substance abuse in the general population, the DSM IV (American Psychiatric Association, 1994) states the prevalence of alcohol abuse to be 13 percent and the prevalence of other psychoactive substance abuse (e.g., marijuana, hallucinogens, cocaine, sedatives, etc.) to be 8 percent. While research is scant on incidence of alcohol and other drug abuse for youth with disabilities, such data for adults with disabilities indicate a prevalence rate two to five times that of the general population (Greer et al., 1985). All disability groups studied indicated a higher incidence of alcohol and other drug abuse than in the general population, but substance abuse was much more prevalent with certain types of psychiatric disabilities than with physical disabilities. Given this, one could conclude that the alcohol/drug abuse rate probably is also higher for school-age youth who have disabilities, particularly considering that the factors contributing to being at risk for substance abuse hold across all disabilities at all ages.

More research on alcohol and drug use (Tyas \& Rush, 1993) and on alcohol and drug treatment with populations who have a disability (Glow, 1989) is needed. One of the major issues in diagnosis of substance abuse in people with disabilities is that the abuse is viewed as a secondary diagnosis with the disability being recognized first, if the abuse is recognized at all (Benshoff \& Riggar, 1990; Kircus \& Brillhart, 1990).

The substance abuse among individuals with disabilities may, in part, have caused the disability, may have an impact on rehabilitation through behavioral or cognitive changes or medical problems, and may affect vocational rehabilitation (Heinemann, Mamott, and Schnoll, 1990).

\section{Risk Factors}

McMahon (1994), Beck, Marr, \& Taricone (1994), and Helwig and Holicky (1994) state that a greater likelihood of substance abuse among populations with disabilities occurs because they have; easy access to drugs, desires to avoid reality, frustration from social alienation, lack of appropriate prevention and information about their disability in association with substance abuse, little knowledge about their medication management, serious health concerns in conjunction with their disability, chronic pain (for some), family issues and problems, feelings of greater differences than peers, few social supports, high unemployment rates, too much idle time, and enabling families, friends, and professional helpers-who often condone drug abuse to avoid confrontation.

Greer, et al., (1985) also indicate that individuals who have disabilities, both congenitally or through acquired disability, are exposed to a set of factors that place them at high risk for substance abuse. The first of these factors is easy access to prescription drugs for valid medical uses such as relieving pain or muscle spasm. The ability to self-medicate for symptoms, in combination with other physiological, emotional, or environmental factors that increase risk for substance abuse, can facilitate the progression from use to abuse.

A related factor is unnecessary medical intervention leading to addiction of prescription medications. Schaschl and Straw (1989) indicate that the majority of congenitally disabled individuals had been prescribed mood-altering medication since early childhood. According to Hepner, Kirshbaum, and Landes (1980/81), 41 percent of clients with disabilities whom they surveyed at a center for independent living received prescriptions for psychoactive drugs that the clients did not believe were needed. Valium, the most frequently prescribed and abused drug among people with disabilities, is commonly prescribed to be taken once a day or as needed.

Other contributing factors appear to be frustration, oppression, or social isolation that some individuals with disabilities experience and seek to escape through substance abuse. In addition, many individuals with disabilities have found themselves surrounded by family, friends, medical practitioners, and others who, by their attitudes, implicitly condone substance abuse. Examples of this would be the doctor who feels helpless to cure a person's disability but who feels helpful by relieving pain through use of medication, or the family and friends who condone alcohol or substance abuse as an acceptable escape (Greer, 1986).

Some studies (Heinemann, Doll, \& Schnoll, 1989; Moore \& Polsgrove, 1989) conclude that substance abuse is often a precursor of acquired disability, rather than vice versa. This is true for a majority of persons who experience traumatic brain injury or spinal-cord injuries, which often occur as a result of automobile or motorcycle accidents. Many of these persons continue to abuse alcohol or other drugs following injury. The counselor should be alert to the fact that substance abuse is more prevalent in clients with traumatic brain injury, spinal cord injury, deafness, and mental illness. 


\section{Specific Disability Data}

The following provides an overview of information related to substance abuse within various disability populations. It is well beyond the scope of this chapter to provide in-depth definitions and discussion of these disabilities. The beginning practitioner is referred to Stolov and Clowers' (1981) text for a comprehensive discussion of all body systems and related disabilities.

In a society too frequently preoccupied with defining a person in terms of his/her disability, quality counseling and treatment offers a client an opportunity to define him/herself in terms of his/her abilities. Physical and program accessibility of treatment facilities is the primary issue for the majority of individuals who have a disability and abuse substances. The following discussion by disability identifies these accessibility issues.

\section{Traumatic Brain Injury}

Traumatic brain injury, TBI, occurring when a blow or outside force is applied to the head or as a result of stroke or anoxia caused by a heart attack, is the disability most commonly associated with co-existing substance abuse or dependence. Annually, an estimated 50,000 to 70,000 Americans experience head injuries resulting in neurological impairments, and a total of more than a million Americans suffer ongoing neurological problems or loss (National Institute on Disabilityand Rehabilitation Research, 1994). Alcohol is linked to at least half of all automotive (the leading cause of head injury) and bicycle accidents and is even more commonly associated with head injuries caused by violence. As might be expected, males in their late adolescent and early adulthood years are at greatest risk for traumatic brain injury (Naugle, Cullum, \& Bigler 1990).

The data clearly indicate that drugs and alcohol are closely linked to the etiology of traumatic brain injury. Many individuals suffer injury as a result of acute intoxication or drug use and some individuals have accidents as a result of hangovers or withdrawal. Still others are victims of drunk or drug impaired drivers. Yet, evidence is equally clear that trauma center personnel often fail to evaluate or identify alcohol or drug use or abuse as a precipitating event, and fail to make appropriate referrals for drug and alcohol evaluations and treatment (Shipley, Taylor, \& Falvo, 1990).

Some individuals with TBI lose the ability to integrate and analyze information or have great difficulty in comprehending simple concepts. Recognizing this, Peterman (1996) has rewritten the 12-Steps in more concrete language. Others may experience problems related to attention span deficits or concentration skills. They may be unable to focus on a task, or may have difficulty following the sequences required to complete a task, or may be easily distracted. In part, these deficits may be related to long-term memory loss. Because they act and behave differently, individuals with TBI may be wrongly labeled and stigmatized, especially by the lay public, as mentally retarded or mentally ill. This can present problems for their participation in peer self-help recovery groups like AA and NA. Peterman (1996) has rewritten the 12-Steps to be more easily understood by this population.

\section{Deaf and Hard of Hearing}

Hearing loss, referred to as hard-of-hearing, is a common impairment affecting 20 million Americans, especially as they age. Another two million Americans have no functional hearing and are considered to be deaf. Research data suggest that the prevalence of drug and alcohol problems among individuals who are deaf or hard of hearing at least approximates if not exceeds the rates of drug and alcohol problems in the general population (Guthman, Lybarger, \& Sanderg, 1993; Renwick \& Krywonis, 1992). Guthman et al.(1993) report that few individuals who are deaf are seen in drug treatment. One barrier is the obvious communication barrier presented by deafness. Another is that, feeling stigmatized and isolated from the general population by deafness, individuals who are deaf are unwilling to assume the added burden within their culture of the label of alcohol or substance abuser.

Five main barriers to substance abuse treatment and recovery exist for this population. They include a general lack of awareness of the problem and a stigma about having such a problem. A close communication network among individuals who are deaf also influences the degree to which they will, in counseling, discuss their problems with alcohol/drugs. Inaccessible resources providing information and services on alcohol and drug addiction and enabling alcohol and drug use behaviors by family members and friends, who may continually rescue these individuals from the consequences of their behavior, are also problems. High costs to receive treatment, 
which may require traveling long distances to receive assistance from staff that are specially trained, also exist.

Assessment is similar to that of other populations with addictions. Examination of physical, work, school, social, legal, financial, emotional, and spiritual aspects of the person's life with specific emphasis on his/her possible relationship with alcohol/drug-related problems is appropriate. It is important to remember that approximately $75 \%$ of Americans who are deaf use American Sign Language (ASL) as their preferred mode of communication (Vernon \& LaFalce, 1990). Completing an assessment interview related to the addiction with this population requires that the counselor be fluent in ASL or utilize a qualified interpreter to ensure accurate communication. It is recommended that assessment include evaluation of communication skills, knowledge of chemical dependency, coping skills, decision-making skills, and the need for occupational and recreational therapy (Guthmann, et al, 1993).

Access to treatment can be enhanced for this population through telecommunication devices (TDD), presence of sign language interpreters and counselors, and outreach contacts (McCrone, 1982). In treatment with this population, it is recommended that time be spent addressing defenses, educating and discussing feelings, attending a special focus group on deaf issues, working with the 12-Steps of Alcoholics Anonymous, addressing selfesteem issues, and involving families (Guthmann, Swan, \& Gendreau, 1994).

Finally, aftercare planning is important in working with this population. Rehabilitation counselors or other counseling professionals providing services to people who are deaf or hard of hearing should be able to provide information about support resources in the client's community. They should empower the client to advocate for himself or herself within the community.

\section{Mental Illness}

One third of the U.S. population will experience a mental disorder at one time in their lives and approximately $50 \%$ of all people with mental disabilities are also experiencing substance abuse problems (VSA, 1992). There is a wide range of mental health disorders which are more common with people who have substance abuse problems. The following ratios are especially telling; a 15.6 times greater rate of antisocial personality disorder, a 5.8 times greater rate of bipolar and depression mood disorders, a 5 times greater rate of anxiety disorders, and a 10.9 times greater rate of other poly substance use disorders (Kelley \& Benshoff, 1997).

Many individuals with the dual diagnosis of substance abuse and mental illness formerly were institutionalized in state-operated facilities for the mentally ill, but the development of new psychotropic medications and the continuing movement toward deinstitutionalization has resulted in more community-based care. A substantial number of these people are homeless, or live in marginal housing situations, with little consistent contact with either substance abuse or mental health service providers. As a result, their treatment regimens may be dictated more by economic factors, crisis situations, or legal sanctions than by need.

Both chronic mental illness and substance abuse are conditions with high levels of relapse. Individuals with these as dual disorders are seen as more challenging to treat and as having poorer outcome prognoses than individuals with single disorders (Kelley \& Benshoff, 1997). Some individuals may develop mental illnessrelated functional limitations as a result of long-term psychoactive substance dependency. They may, for example, become depressed as a result of familial, social, or vocational losses experienced as a result of chronic alcohol or drug dependence. Exogenous depression is closely linked to long-term alcohol consumption and chronic marijuana usage (Buelow \& Hebert, 1995). Others have a pre-existing mental illness preceding the onset of substance dependence. The substance abuse problem is either a symptom or behavioral pattern of the mental illness, or a mechanism to hide or mask the mental illness, or a self-medication of the mental illness.

Specialized programming, variously referred to as Mental Illness-Chemical Abuse (MICA), Mental IllnessSubstance Abuse (MISA), Substance Abuse-Mental Illness (SAMI) programs, and commonly known as dual diagnosis programs developed as the demand and need for services have grown in recent years. The traditional outcome usually sought for both mental illness and substance abuse is entrance into and maintenance of recovery status. For individuals with substance abuse problems, this has traditionally meant abstinence from substance abuse, and resumption of successful functioning in family, community, and vocational spheres, usually supported by participation in peer self-help groups (i.e., Alcoholics Anonymous). For individuals with mental illness, recovery is usually viewed as successful functioning in the community, participation in pharmacologic treatment, avoidance of in-inpatient hospitalization episodes, and supportive outpatient counseling or case management services. Individuals recovering from dual diagnosis are best treated through an approach that combines the best elements of both recovery strategies. Individual or group counseling or pharmacologic medication alone is 
significantly less effective than approaches that combine counseling, medication, education, and psychosocial interventions based on a variety of community supports and services (Kelley \& Benshoff, 1997). Studies reveal that individuals who receive a variety of substance abuse education and psychosocial community support services do significantly better than individuals who receive little or nothing in the way of education and support (Crump \& Milling, 1996; Jerrell, 1996).

\section{Mobility Disabilities}

Many disabilities, such as spinal cord injuries, arthritis, muscular dystrophy, and cerebral palsy, cause functional impairments in the realm of mobility. Approximately 25 million people of the United States population have a mobility disability and one million of these individuals use wheelchairs as their principal means of mobility. Over 9 million individuals have orthopedic impairment and/or arthritis (VSA, 1992). Spinal cord injury (SCI) occurs in 25 to 35 Americans per million citizens each year and affects approximately 259,000 Americans, with young males who engage in high risk behaviors such as driving too fast, diving, and rock climbing comprising the greatest prevalence group (Heller, et. al., 1996). While the data vary greatly from study to study, alcohol and drug use are thought to be related to spinal cord injury from $25 \%$ to $75 \%$ of the time (Helwig \& Holicky, 1994). Evidence suggests that higher levels of drug and alcohol use occur post injury among individuals with SCI.

O'Donnell, Cooper, Gressner, Shehan and Ashley (1981-82) found that in $86 \%$ of the SCI subjects studied in a vocational rehabilitation facility, alcohol was a factor in their injuries and $60 \%$ of these patients resumed alcohol or drug use after leaving the hospital. Studies throughout the years have revealed similar results: Moore and Polsgrove (1989) found that $35 \%$ of a sample of college students with physical disabilities, used marijuana monthly; Moore and Li (1994) found that both lifetime cocaine or crack use was $28 \%$ for applicants for one state's vocational rehabilitation program; and Wright State University's (1996) SARDI program reported that $50 \%$ and more of persons with spinal cord injury became injured after use of alcohol and/or other drugs and $28.5 \%$ of those evaluated had a high incidence of alcohol dependence. These are catastrophic percentages, many times higher than the general population. Individuals with spinal cord injury may use drugs to self-medicate their physical pain as well as to cope with their feelings of anxiety and depression. Screening for problems with alcohol and drugs as well as careful assessment and appropriate referral are necessary parts of general treatment for individuals with these conditions (Heinemann, 1993).

One of the greatest concerns among individuals with mobility disabilities may be alcohol-drug and drugdrug interactions. The standard treatment course for many includes analgesic and anti-inflammatory medications, the effects of which may be potentiated by alcohol or illicit drug consumption. Alcohol is used by this population to self-medicate physical pain. This is a dangerous practice since multiple prescriptions for pain relief medications often may be obtained from multiple physicians, a practice referred to as polypharmacy (Falvo, Holland, Brenner, \& Benshoff, 1990). Another medication interaction problem for individuals with SCI relates to the use of marijuana by some to control muscle spasticity. Long-term marijuana use presents pulmonary and depressed immune system problems.

Physical access is primarily the major issue to overcome in accessing community treatment services for this population.

\section{Blind and Visually Impaired}

About 4.25 Americans have severe visual impairment, defined as the inability to read ordinary newsprint with glasses or contact lenses. The vast majority of them are more than 55 years of age, with 600,000 of them being legally blind (Dickerson, Smith, \& Moore, 1992). For practical purposes, blindness is usually thought of as the inability to perceive light, while visual impairment implies a loss of function as a result of visual limitations (Moore, 1992). Very limited data exist about the prevalence of substance abuse as a co-existing disability, but studies suggest that individuals with visual impairments have drug and alcohol problems at significantly higher rates than the general population and that this is an underserved population in drug and alcohol treatment. Nelipovich, Wengin, and Rossick (1998) estimate that between 220,000 and 330,000 individuals with visual impairments "may require treatment for addiction." (p.1). Too much isolation, time "on their hands", and lack of employment are risk factors for substance abuse in this population (Nelipovich et al. 1998).

Glass (1980-81) reported two kinds of drinkers who are blind and visually impaired, the client who drank before acquiring the disability (Type A) and the client who drank after the disability occurred (Type B). Glass 
states that the Type A client uses drinking as a main coping mechanism and requires substance abuse treatment. The Type-B client may be able to stop abusing alcohol if the underlying stressors are resolved in combination with skill acquisition to assist the person in coping with his or her disability. The Type-A client needs psychological or psychiatric help to assist with life problems that existed prior to the disability. This treatment has a skills training component to assist the individual in copying more effectively with his or her problems. The Type-B client needs to learn skills to be able to be more independent. Either abstinence or controlled drinking may be recommended for this individual (Glass, 1980-81).

Barriers to treatment include the following. As non-drivers, individuals with visual disabilities do not get arrested for driving under the influence, and are not referred to treatment through this process. Many individuals with visual impairments are employed in homebound settings, or in independent businesses set up under the provisions of the Randolph-Shepherd Act, and lack employer recognition and referral for job related drug and alcohol problems. Finally, many drug and alcohol treatments and prevention services market their availability through visual media: newspapers, posters, flyers, and magazines. These marketing efforts are inaccessible to individuals with visual disabilities.

Other treatment barriers include treatment centers often relying heavily on treatment activities such as bibliotherapy requiring visual skills. Clients are expected to read AA or other treatment literature, and are often required to write journals and accounts or both, of their drinking and drugging experiences. While most treatment materials are available in large print or Braille, the ability of individuals to use either format is widely variable. Videos are another popular treatment tool which may have limited utility with this population.

Other problems arise because of the extensive use of group therapy in drug and alcohol treatment. Individuals with visual difficulties may have difficulty tracking the flow of the group dialogue, and they risk missing many of the visual clues that are an important and rich component of group therapy. It is especially important with this population to supplement group therapy.

\section{Attention Deficit/Hyperactivity Disorder}

Barreda-Hanson \& Kilham (1997) define Attention Deficit Hyperactivity Disorder (ADHD) as a "developmental disorder characterized by developmentally inappropriate degrees of inattention, overactivity, and impulsivity" (pg. 34) with essential features being hyperactivity, impulsivity or both (Katisyannis, Landrum, \& Vinton, 1997; D’Alonzo, 1996).

A person with $\mathrm{ADHD}$ characteristics is diagnosed in either of the following categories: combined type, inattentive type, or hyperactive-impulsivity type (Porter, 1997). A person categorized as inattentive type presents such characteristics as task incompletion and being easily distracted (D'Alonzo, 1996; Barreda-Hanson \& Kilham, 1997). Hyperactive characteristics include being "fidgety," "squirmy," (Looff, 1990) talking excessively, and always being 'on the go' (Barreda-Hanson \& Kilham, 1997). Last, the impulsive type is characterized as displaying impatient behavior and constantly interrupting or intruding on others (D'Alonzo, 1996; Katisyannis et al. 1997).

Diagnosing $\mathrm{ADHD}$ is difficult because the individual often displays other behaviors such as "conduct disorder, developmental learning disorders, and oppositional defiant disorders" (Barrickman, Noyes, Kuperman, Schumacher, \& Verda, 1991,pg. 762) and many individuals, in early childhood, display overactive and distracting behaviors. Thus, the diagnosis to insure accuracy must come from a professional specializing with individuals with ADHD (Barreda-Hanson \& Kilham, 1997).

Christian, Kerr, Sutphin, \& Poling (1997) found that $80 \%$ to $90 \%$ of the individuals diagnosed with ADHD received stimulant medication at some point in their life, with the most common and effective stimulant medication being Ritalin. Ritalin is prescribed in an attempt to reduce hyperactivity and distractibility and improve compliance and attention span (Barreda-Hanson, \& Kilham, 1997; Coger, Moe, \& Serafetinides, 1996; D'Alonzo, 1996. Porter (1997) recommends that the decision to prescribe medication should be based on the severity of the condition, attitudes of the parents and child, and capability for supervised medication regime from parents and teachers.

About $3 \%$ to $5 \%$ of the general population in the United States have a diagnosis of ADHD (Katisyannis, Landrum, \& Vinton, 1997; Barrickman, Noyes, Kuperman, Schumacher, \& Verda, 1991; Porter, 1997; D'Alonzo, 1996). The ratio of male to female diagnoses usually varies from $4: 1$ to as much as $9: 1$ (Katisyannis et al.1997).

About $40 \%$ to $50 \%$ of the children with ADHD have coexisting disorders such as conduct disorder, oppositional defiant disorder, learning disorder and emotional difficulties (Schubiner, Tzelepis, Isaacson, Warbasse, Zacharek, \& Musial, 1995; D'Alonzo, 1996). Adams \& Wallace (1994) identify a strong correlation between 
adolescents with $\mathrm{ADHD}$ and conduct disorder and the abuse of substances. Thus, an early childhood diagnosis of ADHD is recognized as a risk factor for adolescent substance abuse (Jaffe, 1991). In adulthood, alcohol and other drug abuse occurs in over 50\% (Hechtman, L. \& Weiss, G. 1986).

According to Jaffe (1991), individuals with ADHD that are taking stimulants or antidepressants self-medicate in that they can use the medications to achieve desired effects. Porter (1997) found that approximately $10 \%$ of adults with ADHD engage in drug abuse. Individuals with mental disabilities usually use and abuse substances for relief from the disability, in the hopes of gaining social acceptance and escaping the realities of the disability (Coger et al.1996).

Individuals with a diagnosis of $\mathrm{ADHD}$ have academic problems, poor socialization skills, and low selfesteem (D'Alonzo, 1996; Porter, 1997). Thus, they have difficulties maintaining relationships with peers and family members. Barreda-Hanson \& Kilham (1997) indicate that individuals with ADHD also have low frustration tolerance and have difficulties in attending well to stimuli. Thus, prevention and treatment issues will have to target some of these behaviors.

The goals of treatment programs are to help individuals obtain abstinence and restructure life goals and processes (Inaba, et al.1997). Treatment techniques with individuals with ADHD utilize a multi-modal approach (Barreda-Hanson \& Kilham, 1997; Katisyannis et al.1997; D’Alonzo, 1996) consisting of family/individual therapy, full individual assessment, and support from a team composed of medical practitioners, counselors, teachers, and parents.

\section{Mental Retardation}

Individuals who have mental retardation experience a range of cognitive impairments related to assimilation, organizing, and expressing their experience in the world. Few studies have studied conclusively the related problem of substance abuse with this population; however, it appears that the number of problems associated with substance abuse for this group does not differ significantly from the substance abuse problems in the general population (DiNitto and Krischef, 1984, Krischef, 1986). Factors affecting substance abuse include age, gender, degree of retardation, and residential arrangement, individual, family, or group home. Specific problems include alienation, isolation, acting out, fighting, stealing, decreased school or work productivity, and drug related arrests, (Schwab, 1992).

Individuals who are mentally retarded tend to misunderstand alcohol or other drug prevention and treatment materials. Such materials must be modified to be understood at an individual's intellectual level such as was done with Peterman's (1996) rewrite of the 12-Steps. Information must be kept simple, presented in a very concrete sequence, and clearly defined.

\section{Learning Disabilities}

Individuals with Learning Disabilities (LD) have symptoms of delayed maturation and deficits in attention, psychomotor skills, and memory. Few studies exist providing incidence data on learning disability and substance abuse. However, it is projected that substance abuse rates are as high as in youth with behavior disorders (BD). Youth with LD or BD and educable mental handicap are high-risk populations for developing substance abuse problems.

Learning disabilities impact on individual understanding of prevention or drug education materials as well as treatment information. Fox and Forbing (1991) provide a sequence of activities useful in addressing individuals with a learning disability susceptibility to substance abuse.

1. teach them about the effects of misuse of drugs;

2. assist them with developing effective skills related to their learning disability;

3. help them to develop recreational interests and abilities, and

4. help them enhance their communication skills and social support base.

These suggestions would appear appropriate with individuals with other disabilities.

\section{Counseling Considerations}

People with disabilities experience the same social pressures and psychological stressors that contribute to substance abuse as do people who do not have a disability. In addition, they experience stressors related to social 
stigma and the additional psychological, emotional, and social problems of their disability, which can increase their risk for abuse.

The counseling considerations to be addressed in populations with physical disability, mental disability or both, and concurrent substance abuse relate to areas of counseling already addressed in a general way within this text. These include counselor knowledge of self, counselor knowledge of rates of use and abuse; and counselor skill in assessment, intervention, and use of community support systems and treatment referrals.

Counselor Knowledge of Self: Per Varhely's admonitions in Chapter 5, the effective counselor needs to have great self-understanding and needs to be aware of his/her own biases and stereotyped thinking. This is particularly true in counseling individuals with disabilities and substance abuse problems.

There are many facets to the counseling of each human being. Before the counselor sits down with the client, the counselor must sit down and inventory what biases or stereotypes he or she holds toward persons who have a disability or those who are substance abusers or both. If these biases are unresolved and the counselor is busy dealing with his or her own issues during counseling sessions, he or she can not attend to the client. After confronting self awareness about the substance abuse issue, biases, or both imbedded social stigmas with reference to the disability, the counselor is more able to interact in a therapeutic way with clients and more objectively identify the impact of substance abuse behaviors.

Counselor Knowledge of Incidence Data: Familiarity with information as provided within this chapter on incidence data per disability group is suggested as a minimum requirement for counselors. On-going review of the research literature specific to this area is necessary to continue to stay current in terms of understanding.

Assessment: The initial interview should be conducted in part with individuals with disabilities to identify those clients who have a problem with substance abuse (Page \& Bailey, 1995). Any substance abuse problem of clients needs to be identified and addressed early in the counseling process. It is extremely important that counselors working with individuals with disabilities have preservice and inservice education in incidence and problems of substance abuse, and knowledge of basic signs and symptoms of substance abuse. Counselor anti-enabling behavior must be present along with emphasis on the importance of being sensitive and alert to possible substance abuse problems of clients. Counselors must be prepared with skills and strategies for positive confrontation, cutting through denial, and identifying effective, affordable, accessible treatment.

Early identification of substance abuse in counseling individuals with disabilities is imperative (Hepner, Kirshbaum, \& Landes, 1980-81). "Unless the abuse-addiction is addressed, dealing with the adjustment to a disability will most likely not occur" (Helwig \& Holicky, 1994). Substance abuse behaviors need to be identified as to whether they are a consequence or a response to the individual's disability. Heinemann, Doll, and Schnoll (1989) found that, after certain injuries resulting in a disability, clients who developed substance abuse problems responded better than those who experienced abuse problems before a disabling event.

All too often substance abuse behaviors are viewed as secondary disabilities (Benshoff, 1990) or not recognized at all in medical settings (Shipley, Taylor, \& Falvo, 1990). Helwig and Holicky (1994) pointed out that, in many independent living centers, the majority of counselors do not regularly ask their clients about alcohol or drug use and this lack of assessment influences appropriate treatment and hence outcomes. While the etiology of substance abuse among people with disabilities is complex (Schaschl \& Straw, 1989), a thorough history of substance abuse needs to be evaluated in relation to a client's development of a disability, and the onset of abuse should be scrutinized as to its function in the daily life of individuals with disabilities. This process will facilitate assessment and the choice of appropriate interventions.

Incidence data alone highlights that assessment is a necessary and critical component of the rehabilitation intake and planning process. Counselors should consider using a substance abuse screening instrument such as the SASSI and a structured short interview instrument such as the MAST. If substance abuse is suspected, the agency may require drug testing. These screening measures are pursued not to exclude consumers from service but to better inform counselor and client about the impact of substance abuse problems on counseling goals.

Individual and group counseling needs to be designed to be sensitive to the particular disability and life circumstance of the individual. Accommodations, such as American Sign Language interpreters or educational audiotapes for the visually impaired, need to be utilized in psychoeducation components of counseling. Prendergast, et al.(1990) have suggested that clients be provided more broadly with information about specific drugs and their contraindications, independent living skills, active alternatives to substance use, parent education and 
involvement, counter-enabling education, self-esteem, peer pressure, and the development of constructive formsof sensation seeking. The client should be assisted in developing new social support networks in conjunction with the above.

As the counseling process progresses, it is important for the counselor to maintain a strong counselor client relationship to insure client involvement and progress in exploring which issues he or she desires. If the client is in denial about his/her substance abuse problem, then he or she is not ready to seek treatment or even fully explore the treatment options available. If the client recognizes that he or she has a substance abuse problem, exploration will identify whether the substance abuse problem preceded the disability or visa versa. The counselor should ascertain how much the client knows about his/her disability, about his/her substance abuse problem, and what limitations or issues are of the most concern. During this time, the counselor emphasis is on developing an understanding of client and their perceptions related to problems of substance abuse.

Other areas to explore with the client are those of social and coping skills. These skills are important because they are potential trouble areas that can lead to relapse of the client after successful recovery from the substance abuse. If the client "recovers" without adequate social and coping skills, any stressors have the potential for sending that client into relapse. Therefore, it is incumbent on the counselor to help the client prepare for a world without substance abuse by helping him or her develop more effective social and coping skills. Insuring or developing a good support system (friends or family) with the client can help him/her avoid relapse following treatment.

When the process of counseling reaches to the point of counselor-client determining the treatment options, the counselor is responsible for making sure that the client is afforded enough information to make an informed decision about which treatment offers the best chance of success. The counselor should make available, if appropriate, information in an alternative and cognitively appropriate means. The counselor should help the client determine which services are needed to gain as much independence as possible. The support services will vary by disability and by person.

Counselor use of community supports: Tyas and Rush (1993) report that few agencies provide alcohol and drug treatment services designed specifically for individuals with disability. Thus, individuals with drug and alcohol problems have had difficulty accessing the rehabilitation system, and, correspondingly, individuals with traditional disabilities have been under-served by the substance abuse treatment network. Prior to and even subsequent to the passage of the Americans with Disabilities Act (1990), many substance dependence treatment facilities were not accessible to individuals who use wheelchairs. In many, the nature of therapy and the shortage of qualified interpreters was thought to preclude participation by individuals who are deaf and the abstract nature of many substance abuse concepts was perceived to limit participation by individuals who had developmental disabilities. Transportation and access problems and the extensive use of bibliotherapy also ruled out participation in therapy by individuals with visual problems. Few people with "traditional" disabilities sought treatment and fewer still were served.

It is, however, recommended that individuals with disabilities be treated within typical alcohol and drug treatment programs. This approach only required that the treatment program review specific disabilities to determine what individuals with that disability might require (Glow, 1989). Unfortunately, many treatment programs would prefer to not serve the disabled population (Tyas \& Rush, 1993).

Even when substance abuse treatment services are available and accessible, persons with traditional disabilities face problems accessing aftercare and peer self-help programs. Many AA and NA meetings are held in church basements or similar settings with architectural barriers because the ADA does not require most nonprofit groups to achieve accessibility standards. Individuals who need interpreter services, in many cases, must provide their own at a cost burden that may be prohibitive. Some meetings are held in places inaccessible even by public transportation, ruling out participation by individuals who do not or cannot drive.

\section{Summary}

A review of the literature provides the conclusion that individuals with disability versus those without a disability are more likely to have a substance abuse problem and less likely to get effective treatment. Data suggest $10-40 \%$ of all individuals in treatment for substance abuse have a coexisting physical or mental disability and alcohol rates for certain disabilities such as spinal cord or head injury exceed 50\%. Risk factors are discussed and substance abuse incidence and impact data are provided for several disability groups. Service barriers 
related to these individual disability groups are identified. Barriers across all groups include

1.Denial on the part of the client since the stigma associated with substance abuse keeps individuals with disabilities from seeking service;

2.Inaccessible treatment facilities; and

3.Treatment staff who do not want to work with or do not know how to work with individuals with disabilities.

Given these barriers, counselors should work with providers to resolve architectural, attitudinal, and communication barriers, and discriminatory policies and procedures. They should know providers, effectively coordinate referrals to appropriate treatment facilities, and provide follow-up as needed.

\section{References}

Adams, L., \& Wallace, J. L. (1994). Residential treatment for the ADHD adolescent substance abuser. Journal of Child and Adolescent Substance Abuse, 4, (1), 35-44.

American Psychiatric Association (1997). Diagnostic and Statistical Manual of Mental Disorders (4th ed.). Washington, D.C. Author.

Americans with Disabilities Act. (1990, July 26). Public Law 101-336.

Barreda-Hanson, C., \& Kilham, C. (1997). Attention-deficit hyperactivity disorder in children under five. Australian Journal of Early Childhood, 22, (4), 34-39.

Barrickman, L., Noyes, R., Kuperman, S., Schumacher, E., \& Verda, M. (1991). Treatment of ADHD with fluoxtine: A preliminary trial. Journal of American Academic Child Adolescent Psychiatry, 30, (5), 762-676.

Beck, R., Marr, K. \& Taricone, P. (1994). Identifying and treating clients with physical disabilities who have substance abuse problems. Rehabilitation Education, 5, 131-138.

Benshoff, J. J. (1990). Substance Abuse: Challenges for the rehabilitation counseling profession. Editorial. Journal of Applied Rehabilitation Counseling, 21 (3), 3.

Benshoff, J. J., \& Riggar, T. P. (1990). Cocaine: A primer for rehabilitation counselors. Journal of Applied Rehabilitation Counseling, 21 (3), 21-24.

Boros, A. (1989). Facing the challenge. Alcohol Health and Research World, 13 (2), 101-103.

Buelow, G. \& Hebert, S. (1995). Counselor's resource on psychiatric medications: Issues of treatment and referral, Pacific Grove, CA: Brooks/Cole Publishing Co.

Christian, L., Kerr, C. L., Sutphin, G. E., \& Poling, A. (1997). Reporting of medication regimen in applied studies of persons with mental retardation and ADHD. Research in Developmental Disabilities, 18, (5), 319 237.

Coger, R. W., Moe, K. L., \& Serafetinides, E. A. (1996). Attention deficit disorder in adults and nicotine dependence: Psychobiological factors in resistance to recovery. Journal of Psychoactive Drugs, 28, (3), 229239.

Connecticut Clearinghouse (1998). Substance abuse prevention and disability. (Funded by the Department of Mental Health and Addiction Services) Retrieved March 26, 1999 from the World Wide Web, http:// www.ctclearinghouse.org/fprevdis.hmt.

Crump, M. T., \& Milling, R.N. (1996). The efficacy of substance abuse education among dual-diagnosis patients. Journal of Substance Abuse Treatment, 13 (2), March-April, 141-144. 
D'Alonzo, B. (1996). Identification and education of students with attention deficit and attention deficit hyperactivity disorders. Preventing School Failure, 40, (2), 88-94.

DiNitto, D. M. \& Krischef, C. H. (1984). Drinking patterns of mentally retarded persons. Alcohol Health and Research World, 8, 40-42.

DiNitto, D. M., \& Schwab, A. J. (1991). Substance abuse factors which interfere with entry or reentry into employment. Austin: University of Texas, School of Social Work.

Edgerton, R. B. (1986). Alcohol and drug use by mentally retarded adults. American Journal of Mental Deficiency, $90(6), 602-609$.

Falvo, D. R., Holland, B., Brenner, J. \& Benshoff, J. (1990). Medication use practices in the ambulatory elderly, Health Values, 14 (3), May-June, 10-16.

Fox, C. L. \& Forbing, S.E., (1991). Overlapping symptoms of substance abuse and learning handicaps. Journal of Learning Disabilities, 21 (1), 24-31.

Gallup Poll (1989, August 4). pp. 10, 16.

Glass, E. J. (1980-81). Problem drinking among the blind and visually impaired. Alcohol Health and Research World, 5, 26-30.

Glow, B. A. (1989). Alcoholism, drugs, and the disabled. In G. W. Lawrence \& A. W. Lawson (Eds.), Alcohlism and substance abuse in special populations (pp. 65-93). Rockville, MD: Aspen.

Greer, B. (1986). Substance abuse among people with disabilities: A problem of too much accessibility. Journal of Rehabilitation, 52, 34-38.

Greer, B. G., Roberts, R., May, G., \& Jenkins, W. M. (1985). Identification of substance abuse in a vocational evaluation setting. Journal of Rehabilitation, 54 (3), 42-45.

Guthmann, D., Lybarger, R., \& Sandberg, K. (1993). Providing chemical dependency treatment to the deaf and hard of hearing mentally ill client. Journal of the American Deafness and Rehabilitation Association, 27 (1), $1-14$.

Hechtman, L. \& Weiss, G. (1986). Controlled prospective fifteen year follow-up of hyperactives as adults: Nonmedical drug and alcohol use and anti-social behavior. Canadian Journal of Psychiatry, 31 (6), 557-567.

Heinemann, A. W., (Ed.) (1993). Substance abuse and physical disability. New York: Haworth Press Inc.

Heinemann, A. W., Doll, M., \& Schnoll, S. (1989). Treatment of alcohol abuse in persons with recent spinal cord injuries. Alcohol, Health and Research World, 13 (2), 110-117.

Heinemann, A. W., Donohue, K., Keen, M. and Schnoll, S. (1988). Alcohol use by persons with recent spinal cord injuries. Archives of Physical Medicine and Rehabilitation, 69, 619-624.

Heinemann, A. W., Goranson, N., Ginsburg, K., and Schnolls, S. (1989). Alcohol use and activity patterns following spinal cord injury. Rehabilitation Psychology, 34 (3), 191-205.

Heinemann, A. W., Mamott, B. D., Schnoll, S. (1990). Substance use by persons with recent spinal cord injuries. Rehabilitation Psychology, 35 (4), 217-228.

Helwig, A. \& Holicky, R. (1994). Substance abuse in persons with disabilities: Treatment considerations. Journal of Counseling \& Development, 72, 227-233. 
Hepner, R., Kirshbaum, H., \& Landes, D. (1980-81). Counseling substance abusers with additional disabilities: The center for independent living. Alcohol Health and Research World, 5, 11-15.

Inaba, D. S., Cohen, W. E., \& Holstein, M.E. (1997). Uppers, Downers, All Arounders: Physical and Mental, Effects on Psychoactive Drugs (3rd ed.) Ashland, OR: CNS Publications, Inc.

Jaffe, S. L. (1991). Intranasal abuse of prescribed methylphenidate by an alcohol and drug abusing adolescent with ADHD. Journal of American Academy in Child Adolescent Psychiatry, 30, (5), 773-774.

Jerrell, J. M. (1996). Toward cost-effective care for persons with dual diagnosis, Journal of Mental Health Administration, 23(3), Summer, 329-337.

Katisyannis, A., Landrum, T. J., \& Vinton, L. (1997). Practical guidelines for monitoring treatment of attentiondeficit disorder. Preventing School Failure, 41, (3), 132-136.

Kelley, S. D. M. \& Benshoff, J. J., (1997). Dual diagnosis of mental illness and substance abuse: Contemporary challenges for rehabilitation. Journal of Applied Rehabilitation Counseling, 28, 43-49.

Kircus E, \& Brillhart, B.A, (1990). Dealing with substance abuse among people with disabilities. Rehabilitation Nursing, 15 (5), 250-253.

Krischef, C. H. (1986). Do the mentally retarded drink? A study of their alcohol usage. Journal of Alcohol and Drug Education, 31, 64-70.

Li, L., \& Moore, D. (1998a). Acceptance of disability and its correlates. The Joumal of Social Psychology, 138 (1), 13-25.

Li, L., \& Moore, D. (1998b). Prevalence and risk factors of illicit drug use by people with disabilities. The American Journal of Addictions, 7 (2), 93-102.

Looff, D. H. (1990). Recognizing and treating attention deficit disorders in chemically dependent adolescents. Journal of Adolescent Chemical Dependency, 1, (1), 5-30.

McCrone, W. P. (1982). Serving the deaf substance abuser. Journal of Psychoactive Drugs, 14, 199-203.

McMahon, B. T. (1994). Preface to the special issue on drugs analcohol. Rehabilitation Counseling Bulletin, 38 (2), 82-83.

Moore, D. (1992). Substance abuse assessment and diagnosis in medical rehabilitation. Neurorehabilitation: An Interdisciplinary Journal, 2 (1), 7-15.

Moore, D. \& Li, Li (1994). Substance use among rehabilitation consumers for vocational rehabilitation services. Journal of Rehabilitation, 60 (4), 48-53.

Moore, D. \& Li, Li (1998). Prevalence and risk factors of illicit drug use by people with disabilities. American Journal of Addictions, 7 (2), 93-102).

Moore, D., \& Polsgrove, L. (1989). Disabilities, developmental handicaps and substance misuse. A review. Social Pharmacology, 3(4), 375-408.

National Institute of Alcohol Abuse and Alcoholism (1994). Alcohol Health and Research World, 18 (3), 243, 245. 
National Institute of Drug Abuse (1991) An economical approach to addressing the drug problem in america. Rockville, MD. Author.

Naugle, R. I., Cullum, C. M., \& Bigler, E. D. (1990). Evaluation of the intellectual and memory function among dementia patients who were intellectually superior, Clinical Neurologist,4 (4), 355-374.

Nelipovich, M., Wengin, \& Kossick, R., (1998). The MARCO Model: Making substance abuse services accessible to people who are visually impaired. Journal of Visual Impairment and Blindness, 92(8), 567-570.

O’Donnell, J., Cooper, J., Gressner, J., Shehan, I. \& Ashley, J. (1981-82). Alcohol Health and Research World, 6(1), 27-29.

Ohlmer, V. L. (1992). Undetected substance abuse among vocational rehabilitation clients, Dissertation, University of Arizona.

Peterman, A. (1996). Effects of supportive and conflictual social interventions on cardiovascular responses to stress: Dissertation Abstracts International Section B: the Sciences and Engineering, 56 (9-B), 1996, 5225.

Pope, A. M. and Tarlov, A. R. (Eds.) (1991). Disability in America. Washington, D.C.: National Academy Press.

Porter, L. (1997). Selected perspectives on ADD and ADHD. Australian Journal of Early Childhood, 22, (4), 7 14.

Prendergast, M., Austin, G., and Miranda, J. (1990). Substance abuse among youth with disabilities. Wisconsin Clearinghouse: University of Wisconsin, Madison.

Rehabilitation Brief (1990). Substance abuse and disability, 12(12). Washington, D.C.: National Institute on Disability and Rehabilitation Research, Department of Education.

Rehabilitation Research and Training Center on Drugs and Disabilities (RRTC). (1996). Substance Abuse Disabilities and Vocational Rehabilitation, Dayton OH: Wright State University Counseling Program New York University.

Renwick, R. M., \& Krywonis, M. (1992). Personal and environmental factors related to employment: Implications for substance abuse intervention. Journal of Rehabilitation, 58 (1), 23-27.

Schaschl, S., and Straw, D. (1989). Results of a model intervention program for physically impaired persons, Alcohol Health and Research World, 13 (2), 150-153.

Schubiner, H., Tzelepis, A., Isaacson, J. H., Warbasse, L. H., Zacharek, M., \& Musial, J. (1995). The dual diagnosis of attention-deficit/hyperactivity disorder and substance abuse: Case reports and literature review. Journal of Clinical Psychiatry, 56, (4), 146-150.

Schwab, W. E. (1992). Substance abuse in patients with physical and cognitive disabilities. In M. F. Flemming, \& K. L. Barry (Eds.) Addictive disorders. St. Louis, MO: Mosby Yearbook, Inc.

Shipley, R. W., Taylor, S. M., \& Falvo, D. R. (1990). Concurrent evaluation and rehabilitation of alcohol abuse and trauma, Journal of Applied Rehabilitation Counseling, 21(3), Special Issue, Fall.

Smelter, R. W., Rasch, B. W., Fleming, J., Nazos, P., \& Baranoswski, S. (1996). Is attention deficit disorder becoming a desired diagnosis? Phi Delta Kappan, 77, (6), 429-432.

Stolov, W. C., \& Clowers, M. (1981). Handbook on severe disability. U.S. Department of Education, Rehabilitation Services Administration. 
Tyas, S. \& Rush, B. (1993). The treatment of disabled persons with alcohol and drug problems: Results of a survey of addiction services. Journal of Studies Alcohol, 54, 275-282.

Vernon, M. \& LaFalce, E. (1990). Epilepsy and deafness: The issue of violence, Journal of the American Deafness and Rehabilitation Association, 23 (3), Jan., 64-67.

VSA Educational Services, (1992). Resource Center on Substance Abuse Prevention and Disability. Washington, D.C.

Wright State University (1996). Substance abuse, disability and vocational rehabilitation, Research and Training Center on Drugs and Disability (SARDI). New York: University Press.

Yalom, I. (1995). The theory and practice of group psychotherapy (4th ed.) New York: Basic Books, Inc. 


\title{
Substance Abuse and Disability
}

\author{
Amos Sales
}

\section{Rationale}

Data about individuals with disabilities indicate they are as likely or more likely to abuse alcohol and drugs as others, and are less likely to access treatment for their substance abuse problems. Knowledge about the factors contributing to these situations will help prospective counselors identify prevention, diagnosis, and treatment approaches that offer the most promise for success.

\section{Overview}

This chapter defines disability in a counseling context, identifies incidence of substance abuse among persons with disabilities, and examines possible factors that may contribute to higher risk for substance abuse in this population than among the U.S. population in general. It provides background and rationale needed to implement prevention, diagnosis, and treatment approaches considered appropriate for persons with disabilities who also have problems of substance abuse.

\section{Objectives}

1.To become aware that persons with mental or physical disabilities face equal or greater risks for substance abuse as individuals in the general population, and to review possible reasons for the increased risk.

2.To develop a personal awareness of and means of identifying effective prevention and treatment strategies for individuals with disabilities who have substance abuse problems.

\section{Activities}

These activities will personalize learning related to definitions of disability, factors related to increase abuse of substances in this population, and treatment needs of individuals with disabilities.

\section{Exercise I: Definitions}

1. Have students share whether or not they have disabilities using the definition provided. Approximately half of the class should have a disability. Follow with a discussion based on questions such as these:

- Why is it difficult to share this information with others?

- Why do we perceive this information as private?

- To what degree does each person consider his or her disability to be a handicap?

2.Have students brainstorm examples of communication shortcuts that constitute negative labels and incorrect use of definitions (i.e., "The retarded" instead of "individuals who are mentally retarded"). Discuss personal reactions to these examples.

\section{Exercise II: Myths}

1. Divide students into small groups of twos or threes. Ask them to reflect back on their first encounters with individuals who had disabilities in order to recall their personal reactions and the reasons behind them. Ask students to share their experiences with the class for discussion. An important point to be made in the discussion is that negative attitudes toward individuals with disabilities are overcome through positive personal contact.

2. Divide class into four groups to discuss myths related to each disability. Have students brainstorm and list on newsprint myths and behaviors linked to the myths. Have the groups share their lists for class discussion. 
3. Divide students in small groups and have them brainstorm examples of stereotypes about disabilities that are still evident in the news and entertainment media. Follow with classroom discussion about ways stereotypes have improved or worsened and what can be done to eliminate stereotypes.

\section{Exercise III: Prevention Programming}

1. Group students by twos or threes. Have each group list the types of information and activities related to substance abuse prevention they either remember from their school days or believe might work.

2. Have each group reflect on why these prevention efforts were expected to work, or project how their own suggestions might impact drug-using behavior.

3. Facilitate classroom discussion on what prevention programming worked and what did not. Identify individual differences in response to prevention. Conclude with a discussion about what might work for individuals with disabilities. An important point to be made is that effectiveness depends on the individual, not the disability.

Exercise IV: Treatment Programming

(Follow same three activities above but exchange reference to prevention with treatment.) 


\section{U.S. Department of Education}

Office of Educational Research and Improvement (OERI) National Library of Education (NLE) Educational Resources Information Center (ERIC)

\section{NOTICE}

\section{REPRODUCTION BASIS}

This document is covered by a signed "Reproduction Release (Blanket) form (on file within the ERIC system), encompassing all or classes of documents from its source organization and, therefore, does not require a "Specific Document" Release form.

This document is Federally-funded, or carries its own permission to reproduce, or is otherwise in the public domain and, therefore, may be reproduced by ERIC without a signed Reproduction Release form (either "Specific Document" or "Blanket"). 